\title{
ELSA DE LAVERGNE, La Naissance du roman policier français. Du Second Empire à la Première Guerre mondiale
}

\section{Mariolina Bertini}

\section{OpenEdition}

\section{Journals}

\section{Edizione digitale}

URL: https://journals.openedition.org/studifrancesi/44138

DOI: 10.4000/studifrancesi.44138

ISSN: 2421-5856

\section{Editore}

Rosenberg \& Sellier

\section{Edizione cartacea}

Data di pubblicazione: 1 juin 2021

Paginazione: 237-238

ISSN: 0039-2944

\section{Notizia bibliografica digitale}

Mariolina Bertini, «ELSA DE LAVERGNE, La Naissance du roman policier français. Du Second Empire à la

Première Guerre mondiale», Studi Francesi [Online], 193 (LXV | I) | 2021, online dal 01 juillet 2021, consultato il 15 octobre 2022. URL: http://journals.openedition.org/studifrancesi/44138 ; DOI: https:// doi.org/10.4000/studifrancesi.44138

Questo documento è stato generato automaticamente il 15 octobre 2022

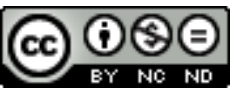

Creative Commons - Attribuzione - Non commerciale - Non opere derivate 4.0 Internazionale - CC BYNC-ND 4.0

https://creativecommons.org/licenses/by-nc-nd/4.0/ 


\title{
ELSA DE LAVERGNE, La Naissance du roman policier français. Du Second Empire à la Première Guerre mondiale
}

\author{
Mariolina Bertini
}

\section{NOTIZIA}

ELSA DE LAVERGNE, La Naissance du roman policier français. Du Second Empire à la Première Guerre mondiale, Classiques Garnier, Paris, 2020, 403 pp.

1 «Du roman populaire au roman policier - scriveva Jacques Dubois nel 1992 - s'observe une filiation qui est sans autre équivalent à l'époque». È proprio questa filiation che troviamo al centro del volume in cui Elsa de Lavergne ha ripreso i risultati della sua thèse diretta da Jean-Yves Tadié. Sinora questa filiation, tanto indiscutibile quanto complessa nelle sue ramificazioni, era stata studiata privilegiando una rosa estremamente ristretta di autori: il pioniere Gaboriau, ispiratore diretto di Conan Doyle; Gaston Leroux, il fortunato creatore del detective-reporter Rouletabille; infine Maurice Leblanc e la coppia Souvestre - Allain, ai quali si devono i due miti trasgressivi del primo Novecento, Arsène Lupin, il gentiluomo cambrioleur, e l'inafferrabile criminale Fantômas. Il grande merito di Elsa de Lavergne è di aver risolutamente allargato l'ottica degli studi precedenti sull'argomento, includendo autori all'epoca prolifici e popolarissimi, come Jules Lermina e Fortuné de Boisgobey, caduti poi nell'oblio e mai più ristampati. Senza questi nomi le ricostruzioni sinora tentate della transizione dal feuilleton al poliziesco mancavano di alcuni tasselli fondamentali, che era veramente urgente ricollocare al loro posto e considerare con la dovuta attenzione.

È con il romanzo giudiziario di Gaboriau che emerge e prende forma il paradigma del futuro romanzo poliziesco. Se nei feuilletons precedenti - come nel mélodrame - le figure di maggior spicco erano le vittime e i giustizieri che accorrevano in loro aiuto, nel romanzo giudiziario il protagonista è l'enquêteur che riesce abilmente a distinguere gli 
indizi rivelatori dalle false tracce disseminate dai colpevoli. Di questa figura Elsa de Lavergne ricostruisce magistralmente la genesi e le trasformazioni. Nel romanzo giudiziario si alternano in un primo tempo rappresentanti della polizia ufficiale e investigatori dilettanti. Intorno al 1900, però, emerge un nuovo protagonista che li surclassa e conquista durevolmente le simpatie del pubblico: il reporter intraprendente e spregiudicato, allegro e coraggioso, ben rappresentato dal Rouletabille di Leroux e da uno degli antagonisti di Fantômas, Fandor. Come giustamente sottolinea Elsa de Lavergne, l'affermazione di questo nuovo eroe è dovuta alla stretta interazione tra cronaca e narrativa popolare. Non è un caso se i due giornalisti che più si distinguono nei reportages su uno dei più celebri delitti del xIX secolo, il caso Troppmann, del 1869, sono Jules Lermina e Eugène Chavette, futuri romanzieri: l'apprendistato nella cronaca nera e nell'ambito delle "cause celebri" sarà fondamentale per arricchire di "effetti di realtà" le finzioni macabre e sensazionali della loro narrativa. Ma il giornalismo non è la sola fonte di ispirazione del nascente romanzo poliziesco. Siamo negli anni in cui il sapere scientifico ispira Zola, Villiers de l'Isle-Adam, Jules Verne; la sua presenza non è meno invasiva nelle opere di Lermina e di altri narratori popolari. Desiderosi di introdurre elementi nuovi in uno schema forzatamente ripetitivo, i pionieri del poliziesco chiedono aiuto alla chimica, alla medicina legale, alla fotografia: i riferimenti scientifici contribuiscono ad ancorare le loro finzioni alla realtà. Dal mondo fantastico del feuilleton i lettori vengono così trasportati in un universo più realistico, che prepara quello del tutto plausibile in cui si muoveranno Maigret e Nestor Burma. 